\title{
Optimal design of a beam stop for Indus-2 using finite element heat transfer studies
}

\author{
A K SINHA, K J S SAWHNEY and R V NANDEDKAR \\ Synchrotron Utilisation Section, Centre for Advanced Technology, Indore \\ 452 013, India \\ e-mail: anil@cat.ernet.in
}

MS received 31 July 2000; revised 11 April 2001

\begin{abstract}
This paper describes the design of an in-vacuum, water-cooled beam stop (X-ray shutter) for the materials science (X-ray diffraction) beamline proposed to be built on the wavelength shifter in the Indus- $2(2.5 \mathrm{GeV})$ synchrotron radiation source. The radiation source impinges $\sim 1 \mathrm{~kW}$ power on the beam stop and the heat transfer capabilities of the beam stop have been evaluated. Temperature distribution in the beam stop has been obtained under various cooling conditions using the finite element analysis calculations with ANSYS software. Design parameters of the beam stop have been optimised. It is also shown that radiation cooling alone is not sufficient for taking away the heat load. Water-cooling of the beam stop is essential.
\end{abstract}

Keywords. Indus-2; synchrotron source; beamlines; finite element analysis; heat load.

\section{Introduction}

Indus-2 (Raja Rao 1998) is a third generation Indian Synchrotron Source, which is under construction at the Centre for Advanced Technology (CAT), Indore. It is a $2.5 \mathrm{GeV}$ storage ring and will give out, from its bending magnets, a continuous spectrum of hard X-rays with critical photon energy of $\sim 6.3 \mathrm{keV}$. A high resolution materials science (X-ray diffraction) beamline is proposed to be put on a 5T, 3-pole superconducting wavelength shifter of the Indus-2 synchrotron radiation source. A wavelength shifter is a 3-pole wiggler, which shifts the critical photon energy to a higher value, compared to the bending magnet radiation. The critical photon energy for the wavelength shifter is $\sim 12 \mathrm{keV}$. The beamline is designed for a photon energy range of 5-25 keV. The wavelength shifter radiates approximately $6 \mathrm{~kW}$ of power, out of which about $1 \mathrm{~kW}$ is admitted in this beamline. In addition, the front end of the beamline is under ultra high vacuum (UHV) of about $10^{-9}$ torr. When this high heat load impinges on any optical component like the beam stop, windows, filters, mirrors or crystals, appreciable thermal distortion takes place because, in UHV, radiation is the only mode of heat transfer. Hence, it is crucial to design in vacuum, properly cooled beamline components, such that the components are able to absorb all or part of the heat radiation emitted by an insertion 
Table 1. Source parameters for the wavelength shifter on Indus-2.

\begin{tabular}{ll}
\hline Electron energy & $2.5 \mathrm{GeV}$ \\
Beam current (maximum) & $300 \mathrm{~mA}$ \\
Critical photon energy & $12.4 \mathrm{keV}$ \\
Magnetic field in wavelength shifter & $5 \mathrm{Tesla}$ \\
Accepted beam divergence $(\mathrm{H} \times \mathrm{V})$ allowed in the front-end port & $12.0 \times 2.0 \mathrm{mrad}^{2}$ \\
Maximum power $(\mathrm{W})$ per mrad $(\mathrm{H})$ & $320 \mathrm{~W} / \mathrm{mrad}^{2}$ \\
Total power entering the front end & $1 \mathrm{~kW}$ \\
\hline
\end{tabular}

device. We have used finite element analysis (FEA) for optimising the cooling arrangements in various beamline components.

In this paper, we describe the heat transfer capabilities of a beam stop (X-ray shutter). In a beamline the beam stop is the component placed just before the front end, facing the source. For this beamline it is possible to place the beam stop anywhere between $8 \mathrm{~m}$ to $10 \mathrm{~m}$ from the source. The beam stop blocks the photon beam when the beamline is not in use or when it undergoes maintenance. FEA software ANSYS (Swanson 1998) has been used to calculate the temperature distribution in the beam stop. The material for the beam stop is copper and the stop is kept normal to the beam. It is cooled by water flow. The design criteria applied is that the temperature at any part of the beam stop should not increase beyond $500^{\circ} \mathrm{C}$, so that it remains well below the melting temperature of copper $\left(1083^{\circ} \mathrm{C}\right)$. Also, the temperature at the interface between copper and water should not exceed $100^{\circ} \mathrm{C}$.

\section{Source parameters}

The photon source is a wavelength shifter on the $2.5 \mathrm{GeV}$ Indus- 2 synchrotron source. Source parameters used for the characterisation of the power distribution are given in table 1 (Raja Rao 1998). The total power emitted by the wavelength shifter is $\sim 6.4 \mathrm{~kW}$ in a horizontal divergence of $(K / \gamma) \sim 150 \mathrm{mrad}$. However, about $1 \mathrm{~kW}$ of power distributed in about $12 \mathrm{mrad}$ horizontal comes out of the output port of the straight section (Ghodke 1999). To be on the safer side, in our calculations we have assumed $1.25 \mathrm{~kW}$ of power impinging on the beam stop.

The size of the photon beam at the beam stop is characterised by the horizontal and vertical divergences and the distance of the beam stop from the source. As discussed above, $\sim 12 \mathrm{mrad}$ of horizontal fan is admitted in the front end. The distribution in this plane is approximately flat. The photon beam is emitted with a Gaussian distribution in the vertical plane. The effective vertical divergence $( \pm 4 / \gamma)$ is found to be approximately $2.0 \mathrm{mrad}$, where $\gamma=1957 \times E(E=$ energy of the electrons in GeV). This gives a maximum photon spot size of $\sim 120 \times 20 \mathrm{~mm}^{2}$ at a distance of $10 \mathrm{~m}$ from the centre of the wavelength shifter.

\section{Finite element analysis}

It is not possible to calculate the temperature distribution of the beam stop analytically because the radiation source distribution is highly anisotropic and also the geometry of the beam stop may be complicated. Therefore, we have used FEA to optimise the cooling arrangement. A cross-sectional view of one quarter of the water-cooled copper beam stop is shown in figure 1 . The dimensions of the beam stop are $120 \times 50 \times 25 \mathrm{~mm}^{3}$. The $8 \mathrm{~mm}$ thick copper wall, which 


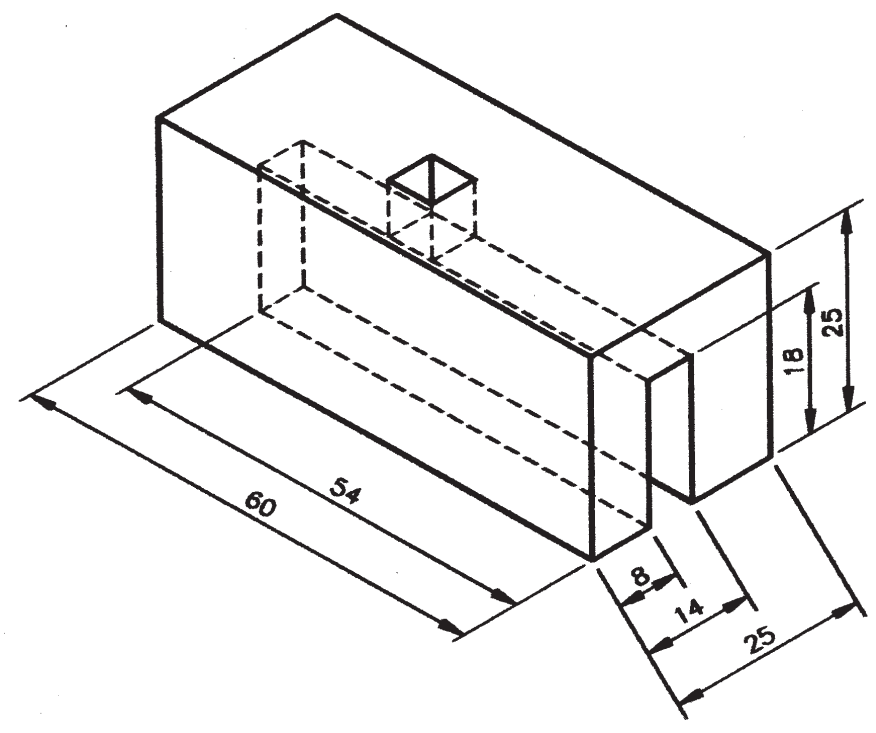

Figure 1. Schematic of a quadrant of the beam shutter made of copper. All dimensions are in $\mathrm{mm}$.

absorbs the radiation, is followed by a $6 \mathrm{~mm}$ thick channel containing $30^{\circ} \mathrm{C}$ water flowing at a rate of $<101 / \mathrm{min}$ for cooling by forced convection. This is the case of streamlined flow. More efficient cooling, if required, can be achieved for turbulent flow (flow rate $>101 / \mathrm{min}$ for this geometry). For streamline flow combined with the geometry of the cooling channel, the average film coefficient $\left(h_{f}\right)$ is calculated using the relation (Eckert \& Drake 1974):

$$
h_{f}=0.664 \operatorname{Pr}^{1 / 3}(u / v \cdot x)^{1 / 2},
$$

where, Pr is the Prandtl number $(\sim 5.5), u=$ velocity of water flow, $v$ is the viscosity of water and $x$ is the distance of water channel from the leading edge. This may be taken as the half length of the channel. Table 2 gives the value of $h_{f}$ as a function of flow rate for the streamlined flow.

However, a flow rate greater than $101 /$ min gives turbulent flow (Reynold's number $\sim 10^{5}$ ). In this regime, the film coefficient is calculated using the equation (Eckert \& Drake 1974):

$$
h_{f}=0.0384 \rho . \mathrm{C}_{\rho} u\left[(u . d / v)^{-1 / 4} /\left(1+A .(u . d / v)^{-1 / 8}\right)(\operatorname{Pr}-1)\right],
$$

where, $A(=1.6)$ is a constant and $d$ is the diameter of the channel. For a rectangular channel, $d$ is the average length of the cross section. For a flow rate of $101 / \mathrm{min}$, we find $h_{f}=$ $1.207 \mathrm{~W} / \mathrm{cm}^{2}{ }^{\circ} \mathrm{C}$.

Table 2. Average film coefficient $\left(h_{f}\right)$ calculated as a function of flow rate for streamlined water flow.

\begin{tabular}{lcc}
\hline Flow rate $(1 / \mathrm{m})$ & Velocity of flow $(\mathrm{cm} / \mathrm{s})$ & $h_{f}\left(\mathrm{~W} / \mathrm{cm}^{2}{ }^{\circ} \mathrm{C}\right)$ \\
\hline 3 & 108 & 0.281 \\
4 & 144 & 0.325 \\
6 & 216 & 0.397 \\
8 & 288 & 0.460
\end{tabular}


Table 3. Power distribution taken as heat load for the FEA calculations. The stop is assumed to be at $10 \mathrm{~m}$ from the source. $\Psi_{1}$ and $\Psi_{2}$ are the vertical angles.

\begin{tabular}{lccc}
\hline$\psi_{1}(\mathrm{mrad})$ & $\psi_{2}(\mathrm{mrad})$ & Power density $\left(\mathrm{W} / \mathrm{mm}^{2}\right)$ & Power density $(\mathrm{W})$ \\
\hline 0 & 0.1 & 2.97 & 356 \\
0.1 & 0.2 & 1.46 & 175 \\
0.2 & 0.3 & 0.52 & 62.5 \\
0.3 & 0.4 & 0.157 & 18.8 \\
0.4 & 0.5 & 0.05 & 6.0 \\
0.5 & 0.6 & 0.025 & 3.0 \\
0.6 & 0.7 & 0.015 & 1.8 \\
0.7 & 0.8 & 0.006 & 0.72 \\
0.8 & 0.9 & 0.003 & 0.36 \\
0.9 & 1.0 & 0.001 & 0.12 \\
\hline
\end{tabular}

It may be noted that the thickness of the wall of the cooling channel, which absorbs radiation, has to be critically determined. This is because, on the one hand, if the wall is very thin the temperature of the copper water interface becomes very high, while on the other, if the wall is too thick the cooling is inefficient. This argument is based on the fact that radiation is absorbed at and near the surface of the beam stop. We have used a computer software XOP (Rio \& Dejus 1998) for calculation of absorption of X-ray radiation in copper. The calculations show that almost all the power is absorbed in the first $1 \mathrm{~mm}$ of the sample and more than $97 \%$ of power is absorbed in the first $0.1 \mathrm{~mm}$ of copper. Therefore, one may assume for the FEA calculations that the total power is absorbed at the surface. Since ANSYS cannot take the actual distribution of radiation from a wavelength shifter as input, which is Gaussian in the vertical plane, we have descretised the load as given in table 3.

To verify the validity of these assumptions and also for bench-marking, we have performed calculations on a similar problem from the literature (Bedzyk et al 1989). Our calculations show that for the absorbed power of $5 \mathrm{~kW}$, the maximum temperature obtained with the above mentioned assumptions is $467^{\circ} \mathrm{C}$ (see figure 2), which compares very well with the literature value $\left(460^{\circ} \mathrm{C}\right)$ obtained with a realistic load. This also shows that our assumptions are conservative because if the real parameters are taken, the maximum temperatures are likely to be lower than the present calculations. We have also confirmed this by taking bulk load in place of surface load. Therefore, for further calculations, we continue to use these assumptions. It is further assumed that the cooling is solely due to convection and radiation loss from all the surfaces can be neglected. The assumption is again justified because heat removed by convection is $1.25 \mathrm{~kW}$ at the steady state, whereas, even if we assume all the surfaces to be at $100^{\circ} \mathrm{C}$ (maximum temperature at the centre), the heat removed by radiation from all the surfaces is only $2.2 \mathrm{~W}$. For the calculation of radiation loss, the emissivity of copper is taken to be 0.1 .

The symmetry of the problem allows us to use one quadrant of the beam stop for finite element analysis. The beam stop material copper is characterised by a temperature dependent thermal conductivity, which is about $0.399 \mathrm{~W} / \mathrm{mm} /{ }^{\circ} \mathrm{C}$ at $30^{\circ} \mathrm{C}$ and drops down to $0.334 \mathrm{~W} / \mathrm{mm} /{ }^{\circ} \mathrm{C}$ at $1000^{\circ} \mathrm{C}$, linearly. 

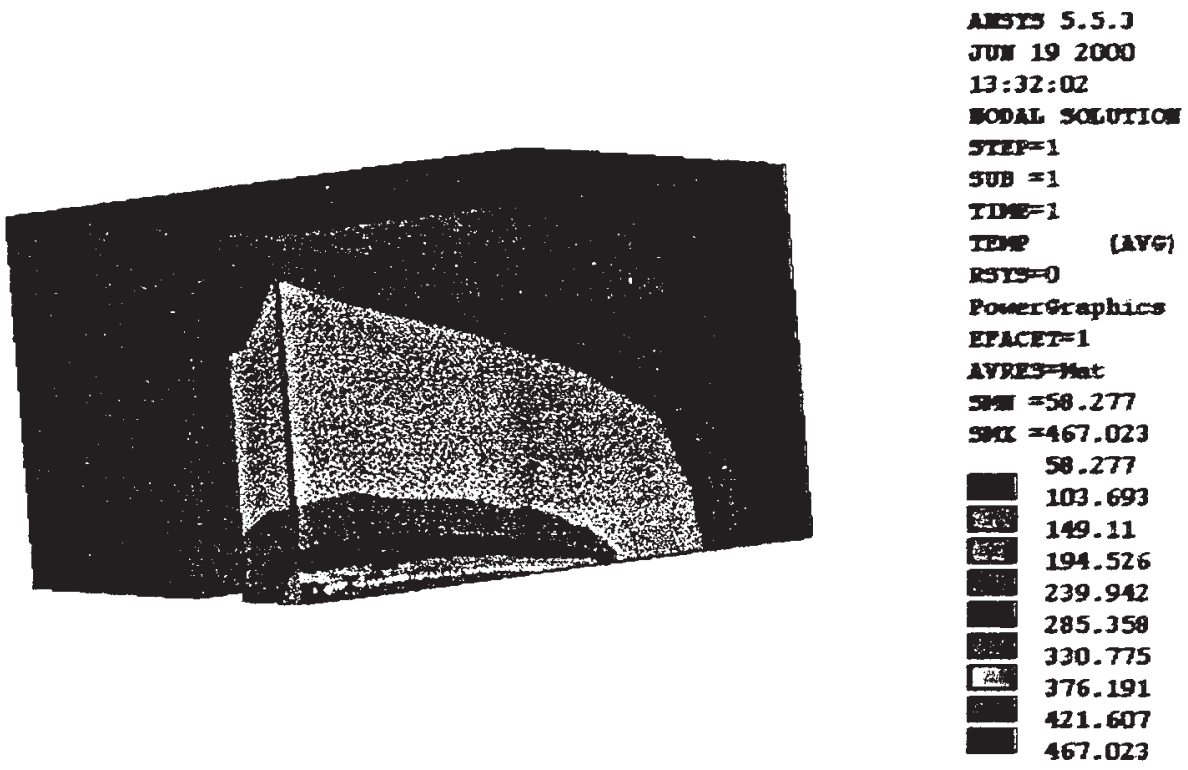

Figure 2. Temperature contours for one quadrant of a water-cooled beam stop for a heat load of $5 \mathrm{~kW}$ from wiggler of the CHESS synchrotron (Bedzyk et al 1989). The calculations are repeated to justify the assumptions made in the present calculations and also for bench-marking.

Figure 3 shows the model of one-fourth of the beam stop used in the thermal analysis along with the meshing. We have used three-dimensional, 20-node, thermal elements (solid90) for the 3-D analysis and the steady state solutions. The meshing has been done with tetragonal free meshing. Element size is less than $1 \mathrm{~mm}$ in the region where the heat load has been applied. For other regions it is about $2-5 \mathrm{~mm}$ or more.

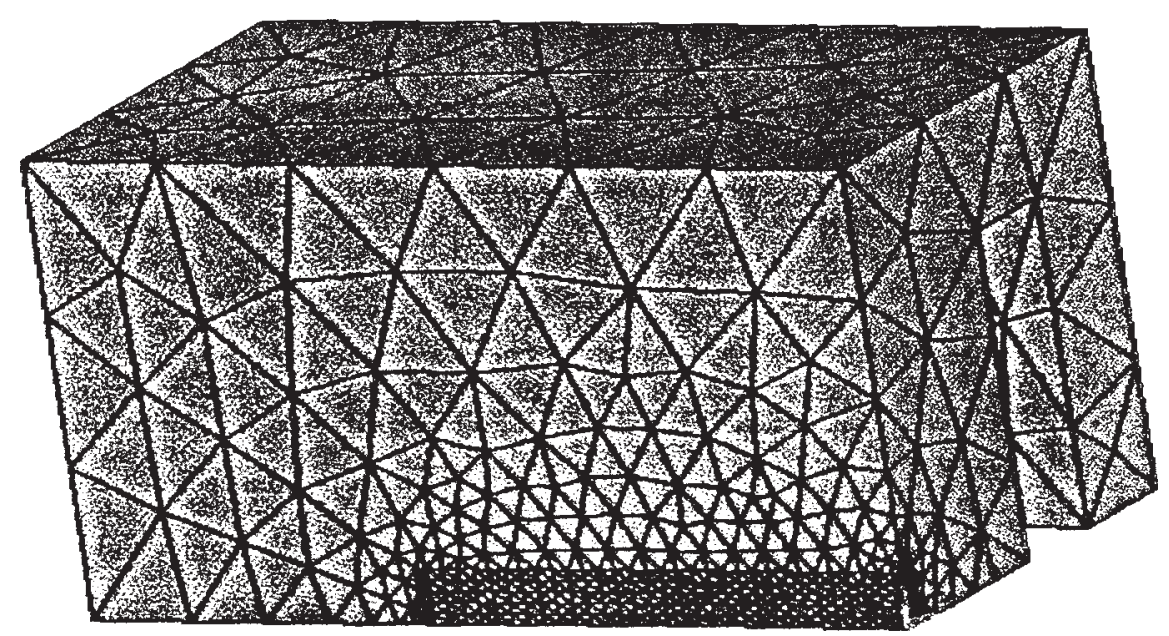

Figure 3. Schematic of a quadrant of the beam stop showing the meshing for finite element analysis. Solid90 (thermal elements) has been used with tetragonal free meshing. The element size is less than $1 \mathrm{~mm}$ in the region where load has been applied. For other regions the element sizes are $2 \mathrm{~mm}$ to $5 \mathrm{~mm}$. 
To determine temperature distribution when the heat loss is assumed to be only due to radiation cooling, which may happen because of accidental stoppage of cooling water flow, we first mesh the beam stop using solid70 finite elements. The global mesh size is $1 \mathrm{~mm}$ on the shorter sides and $10 \mathrm{~mm}$ on the larger side of the stop. The heat load is applied on the surface of the elements. Now the radiation surface elements surf 22 (ANSYS radiation element) are generated using the nodes of the solid70 elements, on four exposed sides of the beam stop. The form factor is taken to be 1 . This allows the overlaid radiation elements to radiate to the environment. Emissivity is again taken to be 0.1 for copper.

\section{Results and discussion}

\subsection{Optimisation of cooling wall thickness}

Optimisation of the wall thickness of the cooling channel is important. We have, therefore, calculated the temperature distributions of the beam stop by varying the wall thickness between

(a)

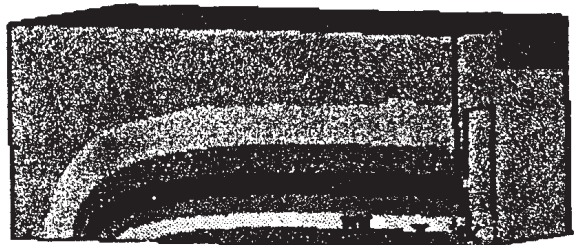

(b)

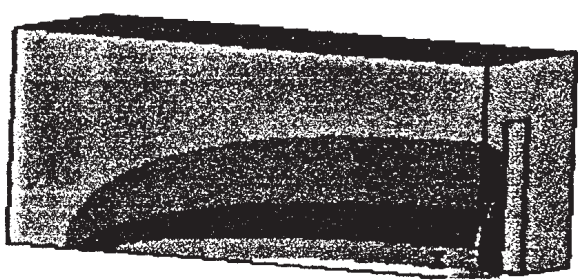

(c)

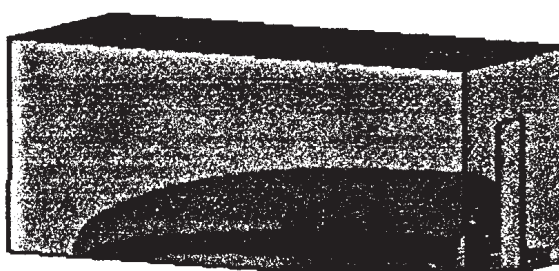

(d)

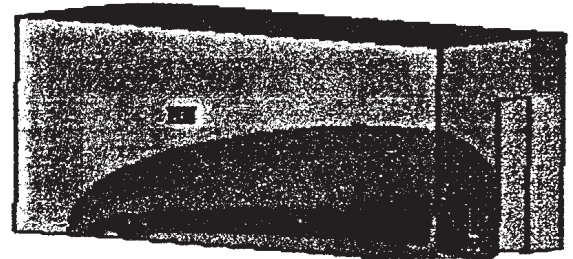

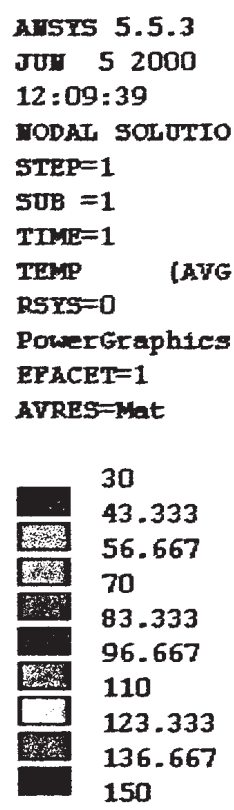

150

Figure 4. Study of optimisation of the cooling wall thickness. Figure shows temperature distribution in one quadrant of the beam shutter for various thicknesses: 2 (a), 6 (b), 8 (c) and $12 \mathrm{~mm}$ (d) of the beam-stop cooling channel. Distance of the beam stop from the source is $8 \mathrm{~m}$ and film coefficient is $0.397 \mathrm{~W} / \mathrm{cm}^{2} /{ }^{\circ} \mathrm{C}$ (water flow rate $\left.=61 / \mathrm{min}\right)$. 


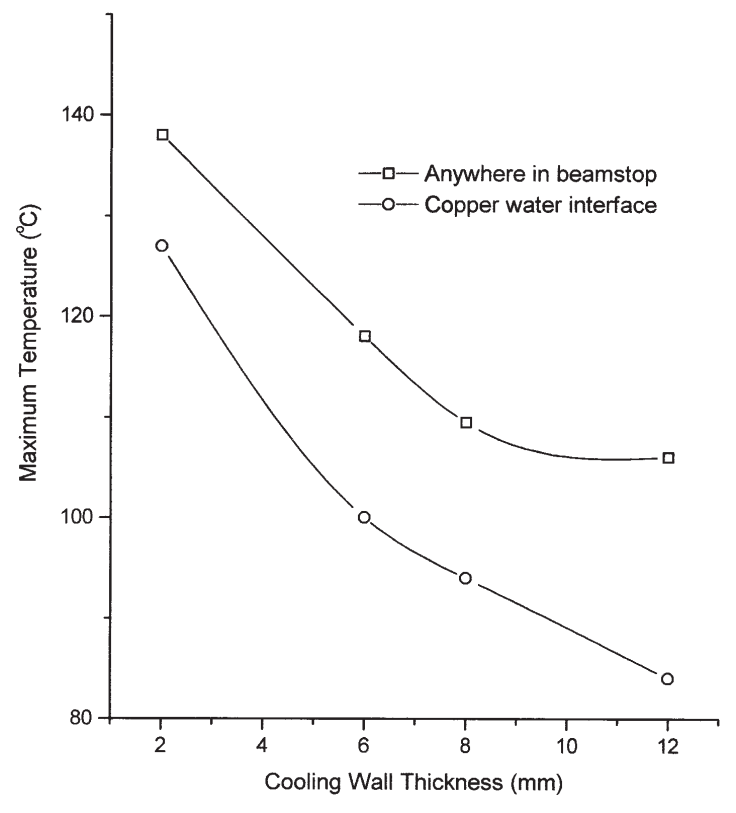

Figure 5. Maximum temperatures of the body of the beam stop as well as that of the copper-water interface plotted as functions of cooling wall thickness. Distance of the beam stop from the source is $8 \mathrm{~m}$ and film coefficient is $0.397 \mathrm{~W} / \mathrm{cm}^{2} /{ }^{\circ} \mathrm{C}$ (water flow rate $=61 / \mathrm{min}$ ).

$2 \mathrm{~mm}$ and $12 \mathrm{~mm}$ and the results are shown in figure 4. For these calculations the beam stop has been kept at a distance of $8 \mathrm{~m}$ from the source. The water flow rate is kept at $61 / \mathrm{m}$. We find that for the wall thicknesses of $2 \mathrm{~mm}$ and $6 \mathrm{~mm}$ the temperatures of copper water interface exceeds $100^{\circ} \mathrm{C}$ (see yellow colour temperature contours in figures $4 \mathrm{a}$ and b), which is outside our design criterion. However, for thicknesses of the cooling channel wall $>6 \mathrm{~mm}$ the temperatures are below $100^{\circ} \mathrm{C}$ (see green colour temperature contour for figure $4 \mathrm{c}$ and lower temperature contour for figure $4 \mathrm{~d}$ ). Therefore, a cooling wall thickness of $8 \mathrm{~mm}$ or more would be suitable for our beam stop. However, although thicknesses greater than $8 \mathrm{~mm}$ give lower temperatures, the cooling efficiency decreases because of the thicker wall between the heat source and water. Therefore, a wall thickness of $8 \mathrm{~mm}$ is found to be optimum in our case. The maximum temperatures of the stop and that at the copper water interface, as the function of cooling channel wall thickness, derived from the above calculations, are shown in figure 5 .

\subsection{Effect of water flow rates}

It is not advisable to use turbulent flow in ultrahigh vacuum environments, as it may lead to mechanical vibrations. Streamlined flow is preferable. Table 2 gives values of film coefficients for various flow rates in streamlined flow. We have calculated the temperature distribution in the beam stop for streamlined flow, for various flow rates between $31 / \mathrm{min}$ to $8 \mathrm{l} / \mathrm{min}$, and the results are shown in figure 6 . We find that for a flow of $41 / \mathrm{min}\left(h_{f}=3.25 \times 10^{-3} \mathrm{~W} / \mathrm{mm}^{2}{ }^{\circ} \mathrm{C}\right)$, the maximum temperature at the copper water interface is $\sim 110^{\circ} \mathrm{C}$ (see $110^{\circ} \mathrm{C}$ temperature contour in figure 6a). This violates one of the design criteria and hence the flow rate of $4,1 / \mathrm{min}$ cannot be used. However, for flow rates of $61 / \mathrm{min}$ and $81 / \mathrm{min}$, the maximum interface temperatures are $\sim 100^{\circ} \mathrm{C}$ and $\sim 89^{\circ} \mathrm{C}$ as shown in figures $6 \mathrm{~b}$ and $6 \mathrm{c}$ respectively. Therefore the beam stop can be cooled with water flowing in the streamlined flow region, with water flow rates between $61 / \mathrm{min}$ and $81 / \mathrm{min}$. 
(a)

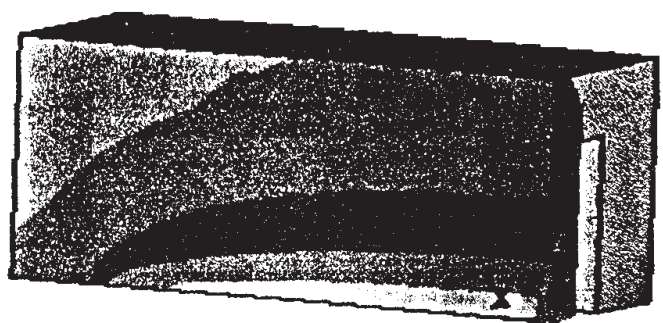

(b)
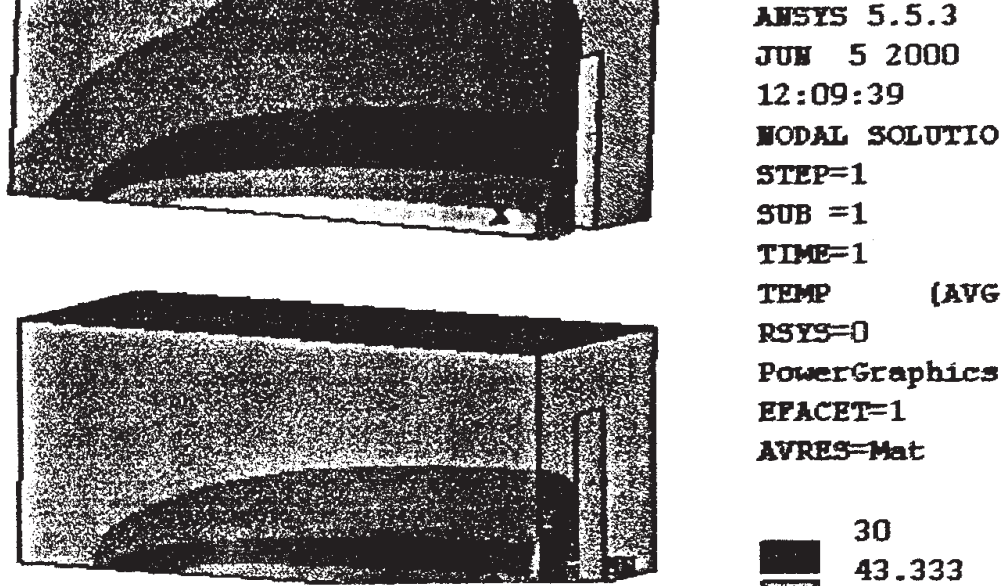

(c)

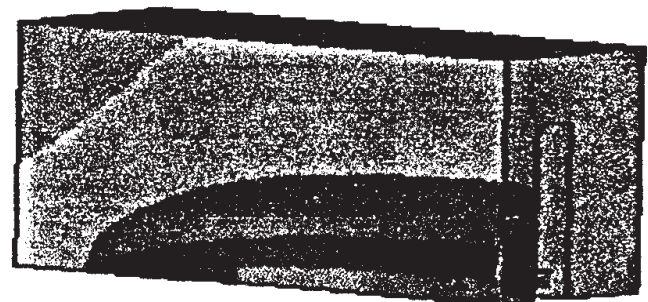

30

43.333

56.667

70

110

123.333

136.667

150

(d)

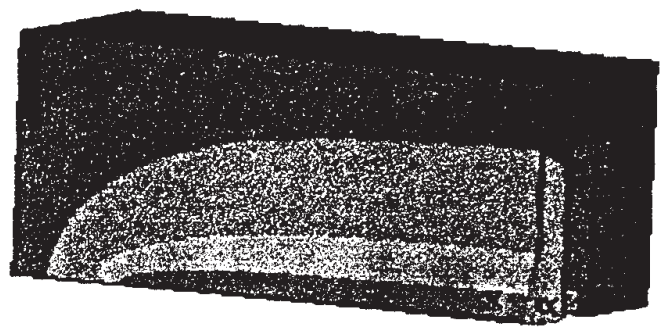

Figure 6. Temperature distributions in one quadrant of the beam stop for various water flow rates: 4 (a), 6 (b), 8 (c) and 101/min (d). The distance of the beam stop from the source is $8 \mathrm{~m}$ and thickness of the cooling wall channel is $6 \mathrm{~mm}$.

For comparison, we have also calculated the temperature distribution for the turbulent flow with a flow rate of $101 / \mathrm{m}\left(h_{f}=0.012 \mathrm{~W} / \mathrm{mm}^{2 \circ} \mathrm{C}\right)$. We find that the maximum temperature of the copper water interface is $68^{\circ} \mathrm{C}$ and the maximum temperature of the beam stop is $\sim 85^{\circ} \mathrm{C}$ (fig. $6 \mathrm{~d}$ ). The maximum temperature of the beam stop and the maximum temperature of the copper water interface as a function of flow rate are plotted in figure 7.

\subsection{Effect of distance of the beam stop from the tangent point}

Since the distance of this component from the source is not yet finalised, we have made calculations for distances between $8 \mathrm{~m}$ and $10 \mathrm{~m}$. The effect of changing the distance of the beam 


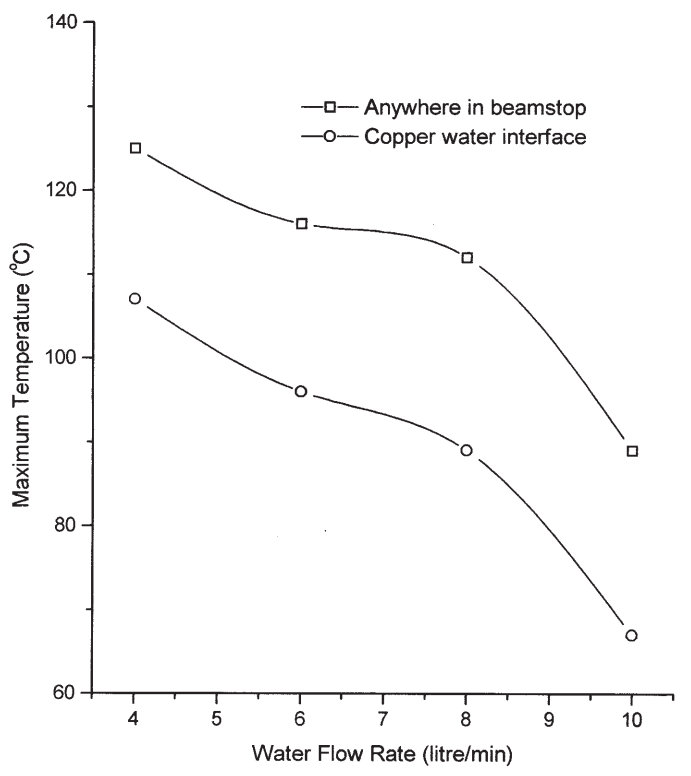

Figure 7. Maximum temperatures of the body of the beam stop and that of the copper-water interface plotted as functions of water flow rates. The distance of the beam stop from the source is $8 \mathrm{~m}$ and the thickness of the cooling channel is $6 \mathrm{~mm}$.

stop from the source has also been investigated and the results are shown in figure 8 . Figure 8a shows the temperature distribution on the beam stop, kept at a distance of $8 \mathrm{~m}$ from the tangent point, for water flow rate of $61 / \mathrm{min}$ and $8 \mathrm{~mm}$ thickness of the copper wall on which the radiation is absorbed. We find that the maximum temperature of the beam stop is $\sim 110^{\circ} \mathrm{C}$ and the maximum temperature of the copper water interface region is approximately $\sim 79^{\circ} \mathrm{C}$. These are the two important temperatures which should meet the design specifications. Both these temperatures are found to be well within the design specifications. Figures $8 \mathrm{~b}$ and $\mathrm{c}$ show that the temperature distributions of the beam stop when it is kept at $9 \mathrm{~m}$ and $10 \mathrm{~m}$ respectively. From the FEA calculations the maximum temperatures of the beam stop and the copper-water interface as the function of the distance of the beam stop are determined (figure 9) and both these decrease with increasing distance of the beam stop, as expected.

\subsection{Safety considerations}

We have also performed calculations for cooling of the beam stop using radiation cooling alone. This is the situation when the water flow stops. Since the beam stop is kept in the ultra high vacuum, the only possible cooling is by radiation as air convection will be negligible. We find that for $1.25 \mathrm{~kW}$ of absorbed power, the uniform temperature of the whole block would be $1270{ }^{\circ} \mathrm{C}$. This temperature depends only upon the total absorbed power and not so much on the distribution of power in the steady state. Therefore, the maximum temperature will not depend upon the distance of the beam stop from the source. Figure 10 shows that the copper beam stop is likely to melt if left to cool by radiation, leading to a catastrophic situation and hence it is very essential to provide adequate interlocks to detect stoppage of cooling water flow. 
(a)

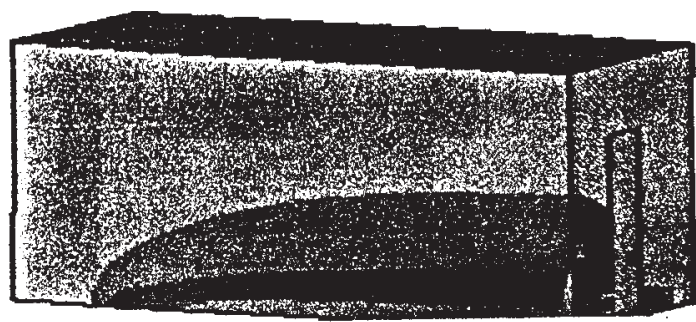

(b)

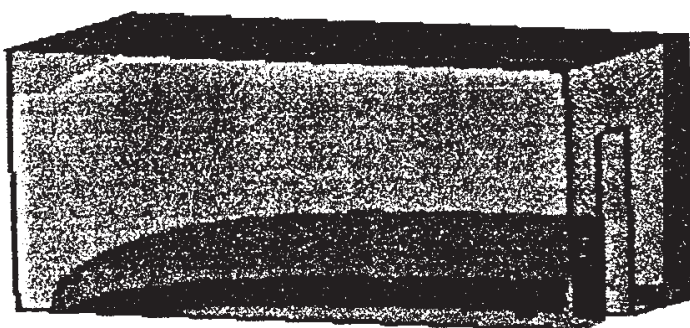

\author{
AISTS 5.5 .3 \\ गUए 52000 \\ 12:09:39 \\ DODAL SOLUTIO \\ STEP $=1$ \\ SUB $=1$ \\ TIMIE $=1$ \\ TEMP \\ CAYG \\ RSTS=0 \\ PowerGraphice \\ EFACET=1 \\ AVREg= wat
}

(c)

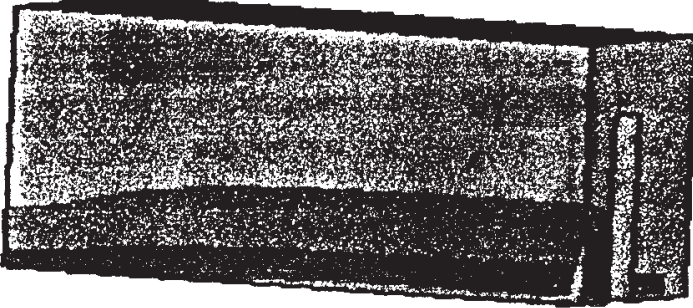

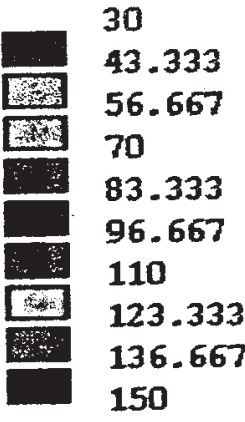

Figure 8. Temperature distribution in one quadrant of the beam shutter for various distances: 8 (a), 9 (b), and 10 (c) of the beam stop from the radiation source. The thickness of the wall of the cooling channel is $6 \mathrm{~mm}$ and film coefficient is $0.397 \mathrm{~W} / \mathrm{cm}^{2} /{ }^{\circ} \mathrm{C}$ (water flow rate $61 / \mathrm{min}$ ).

\title{
5. Summary and conclusions
}

A water-cooled copper beam stop has been designed for the materials science beamline on the Indus-2 synchrotron source. Heat load calculations using finite element analysis have been used to optimise the design. Based on these calculations, the following optimum parameters have been obtained for absorbed power of $1.25 \mathrm{~kW}$.

Copper beam stop of size $120 \times 50 \times 25 \mathrm{~mm}^{3}$ is used, in which an $8 \mathrm{~mm}$ thick copper wall (on which the radiation is absorbed) is followed by a $6 \mathrm{~mm}$ thick channel for water flow. Cooling by the forced convection of water (at an ambient of $30^{\circ} \mathrm{C}$ ) flowing at the rate of $\approx 81 /$ min in streamlined flow regime is sufficient to cool the beam stop. With these parameters, maximum temperature anywhere in the beam stop is $\approx 110^{\circ} \mathrm{C}$ and that of the copper water interface is $\approx 90^{\circ} \mathrm{C}$. Both these temperatures are well within the design parameters.

In addition, the primary safety consideration due to accidental stoppage of water flow has been evaluated. It is seen that for heat load from the wavelength shifter in Indus-2, the temperature rises to approximately $1270^{\circ} \mathrm{C}$ when the water flow stops. This will prove catastrophic and hence water-cooling of the beam stop is essential. 


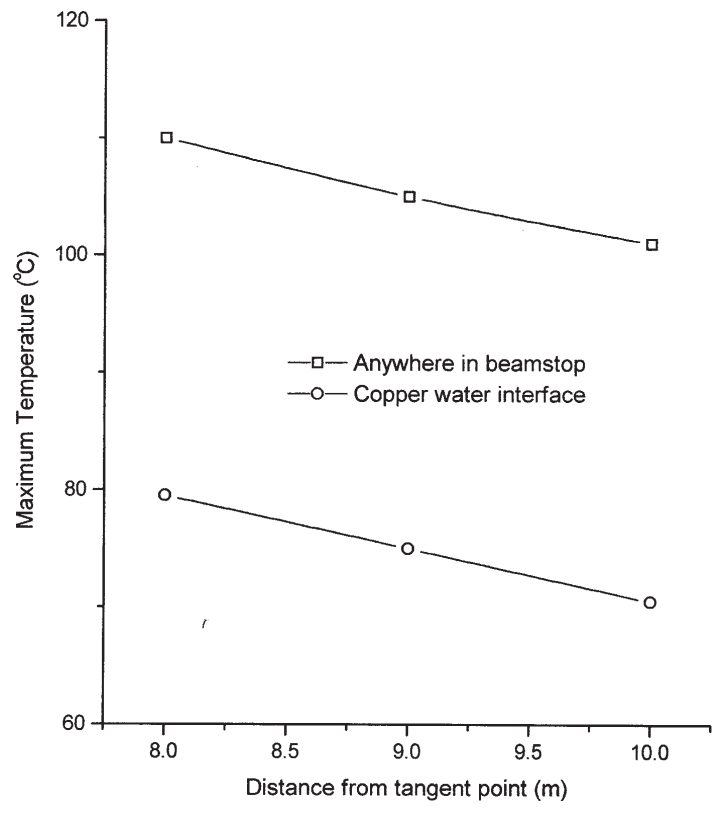

Figure 9. Maximum temperatures of the body of the beam stop and that of the copper-water interface plotted as a function of distance of the beam shutter from the tangent point of radiation. The thickness of the wall of the cooling channel is $6 \mathrm{~mm}$ and film coefficient is $0.397 \mathrm{~W} / \mathrm{cm}^{2} /{ }^{\circ} \mathrm{C}$ (water flow rate $61 / \mathrm{min})$.

With water flow, maximum temperatures of $\sim 110^{\circ} \mathrm{C}$ at the centre of the stop and of about $89^{\circ} \mathrm{C}$ at the copper-water interface have been obtained for the above mentioned parameters, for $8 \mathrm{~m}$ distance from the centre of the wavelength shifter. All the design parameters are valid for other distances as well, up to $10 \mathrm{~m}$. However, for distances greater than $10 \mathrm{~m}$, the size of the beam stop has to be increased.

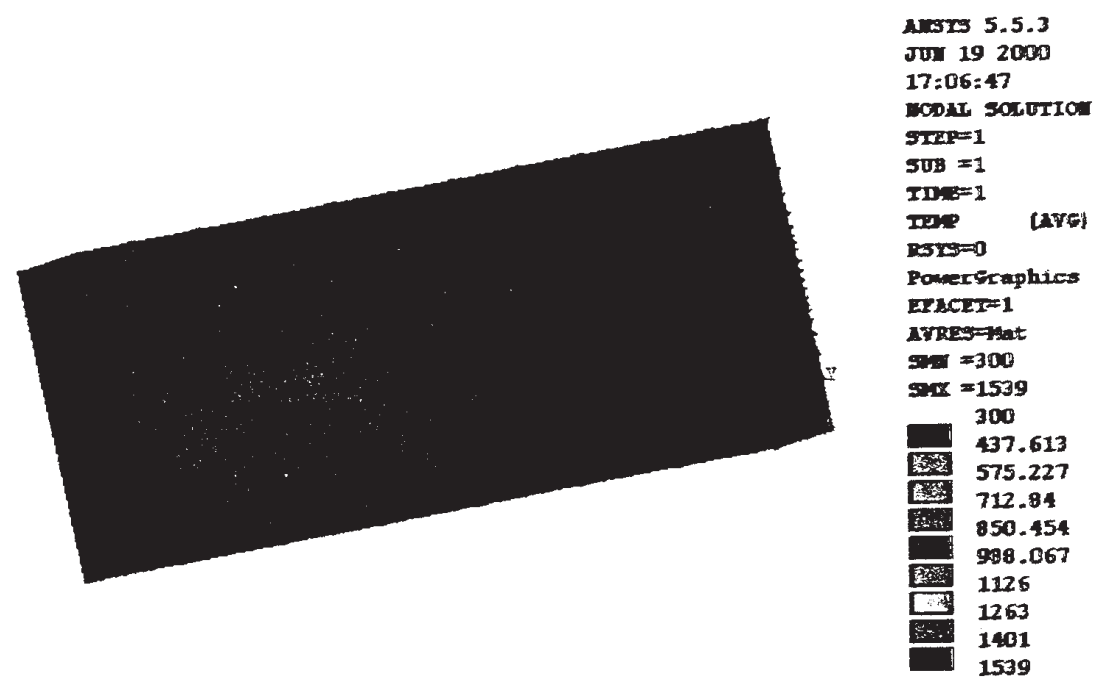

Figure 10. Temperature distribution of the beam shutter when the cooling is taking place by radiation alone (no water flow) in the steady state. The total absorbed power is $1.25 \mathrm{~kW}$. The emmissivity of the surface is 0.1 . 


\section{References}

Ghodke A D 1999 Centre for Advanced Technology, Indore (private communication) Bedzyk M J, Keeffe M J, Schildkamp W, Shen Q 1989 Rev. Sci. Instrum. 60: 1460-1463 Eckert E R G, Drake R M 1974 Heat and mass transfer (New Delhi: Tata-McGraw Hill) chap. 7, 8 Raja Rao A S 1998 Indus-2 project report. Centre for Advanced Technology, Indore

Swanson 1998 Swanson Analysis Systems Inc., PA 15342, ANSYS-5.5, Engineering Analysis Systems

Rio S M, Dejus R J 1998 XOP: New developments. Soc. Photo-Opt. Instrum. Eng. 2448: 340-345; available free at http://ftp.esrf.fr/dist/expg/idl 